\title{
Ciudad, luz y fronteras. Los inicios de Chus Gutiérrez en el cine*
}

\author{
Sagrario Beceiro y Begoña Hervero \\ Universidad Carlos III
}

Chus Gutiérrez (1962) es una directora de cine española. En España se considera a Chus Gutiérrez como una de las más importantes representantes de la actual generación de directoras de cine. Hasta el momento ha dirigido una decena de largometrajes: Sublet (1991), Sexo oral (1994), Alma gitana (1995), Insomnio (1998), Poniente (2002), El calentito (2005), Retorno a Hansala (2008), Ciudad Delirio (2014), Sacromonte, los sabios de la tribu (2014) y Droga oral (2015). En sus películas, siempre con una visión muy personal, ha tratado temas relacionados con la inmigración o la discriminación a las minorías o a las mujeres y, desde una posición más vitalista, ha intentado reflejar el papel de la música y el baile en la sociedad; también temas de corte más íntimo o personal como el insomnio, el sexo o las drogas. Por otro lado, ha sido guionista de cine y televisión, directora de una obra teatral y una serie de televisión, actriz y miembro del grupo musical Xoxonees. Además, le gustaría escribir una novela en un futuro muy cercano.

La presente entrevista es un breve extracto de las conversaciones mantenidas por las autoras con la directora de cine Chus Gutiérrez entre diciembre de 2018 y enero de 2019. En el fragmento seleccionado, la directora nos cuenta su ingreso en la edad adulta, su formación, su papel como miembro del grupo musical Xoxonees, los primeros pasos en el ámbito cinematográfico profesional y la producción de su primer largometraje: Sublet (1991). Podemos afirmar que las palabras de la entrevistada son muy útiles para que cualquier lector interesado pueda comprender aspectos que habitualmente no aparecen en los textos académicos. Sus vivencias son también el reflejo de lo que fue la Transición en España -un periodo de profundos cambios en la sociedad y en las relaciones familiares- y de la evolución del papel de la mujer. Pero, por encima de todo, destaca la naturalidad y frescura con la que Chus Gutiérrez nos cuenta las dificultades que suponía intentar convertirse en directora de cine en la década de 1980. Es desde luego una visión personal e íntima, alejada de otras posibles miradas más elaboradas, pero también más encorsetadas.

Sagrario Beceiro/ Begońa Herrero: Cuando todavía no habías cumplido los 18 años, te vas a vivir a Londres.

\footnotetext{
* Esta entrevista se efectuó el 25 de octubre de 2018.
} 
Chus Gutiérrez: Sí, porque mi madre me dice: "Hija, a ver... tienes que aprender inglés". Porque mi madre tenía y tiene tres máximas: "Una mujer tiene que saber conducir, hablar inglés y escribir a máquina”. Eran sus tres máximas.

SB/BH: ¿Fue tu madre la que te animó a irte a Londres?

CG: Sí, por supuesto, mi madre ha sido una mujer que en ese sentido nunca ha tenido miedo. Mi padre en cambio estaba horrorizado y sí tenía miedo. Él quería que las chicas trabajáramos en El Corte Inglés y mi hermano en el Banco de España. Y mi madre era todo lo contrario, siempre nos ha abierto al mundo: "haced lo que sea", nos decía. Por eso nunca tuve la sensación de ser diferente por ser mujer. Nadie me había dicho que no hiciera nada. Mi madre nunca te trasmitía que estaba más preocupada por ti. Nunca sentí que por ser una mujer había alguna diferencia. Tampoco me lo planteé.

SB/BH: ¿Qué te pareció Londres?

CG: En Londres fue la primera vez que estaba realmente sola. Primero trabajé de $a u$ pair y luego en un hotel. No tenía dinero. Pero bueno... era la primera vez en mi vida que me enfrentaba a mi propia fortaleza y era la primera vez en mi vida que tenía que pensar qué quería hacer. Estuvo bien a nivel personal. Me di cuenta de que tenía mucha capacidad de supervivencia. Fue como un aprendizaje muy bestia.

Londres es muy duro si no tienes dinero, y cuando digo no tener es que pasábamos un montón de hambre. Recuerdo que una chica del piso en el que vivía trabajaba en una pastelería y todas las noches traía una tarta y tomábamos la tarta de cena. Lavábamos la ropa en la bañera. No teníamos mucho contacto con gente inglesa. No había mezcla, solo conocías a gente que estaba como tú, italianos, franceses, polacos.... Recuerdo que lo más duro era la falta de luz. A las tres de la tarde era ya noche... ahí empecé a escribir... un chico me regaló una máquina de escribir y me puse a escribir un cuento, algo que se pudiese leer de principio a fin.

SB/BH: ¿Qué fue lo más destacado de tu experiencia?

CG: Que fue la primera vez que crucé una frontera. En esa época no estábamos en la Unión Europea, había mucha gente que iba a Londres a aprovecharse de la seguridad social inglesa. Recuerdo que, en la vuelta a Londres, después de Navidad, yo ya no era au pair. Y esa era la primera vez que me enfrentaba a una frontera. Podían no dejarme pasar... y eso me cambió... me di cuenta de que los españoles éramos considerados un país pobre y que no éramos bienvenidos. Me impactó. Recuerdo la sensación de miedo, el mundo de la frontera. También me di cuenta de que el traslado de Granada a Madrid en mi infancia ya había sido como un éxodo, la primera emigración. Luego Londres, y luego vino también Nueva York. Esa sensación de no pertenencia.

SB/BH: Pero aprendiste inglés...

CG: Sí, claro [risas].

SB/BH: ¿Cómo fue la vuelta a España?

CG: Al volver nos vamos a vivir -mi novio de aquel entonces y yo- al barrio de Lavapiés, en Madrid y compartimos piso con dos chicos, Nacho y Puga, que estudiaban en la universidad la licenciatura de "Imagen y sonido" -en la actualidad Grado en Comunicación Audiovisual-. Yo estaba aprendiendo a escribir a máquina, tal y como me había dicho mi madre. Uno de ellos me dice un día: "tengo que pasar a máquina este guion” y yo le dije "te lo paso yo". No había leído un guion en mi vida y entonces descubro, 
me doy cuenta, de que es una historia pero que tiene otra forma. Además, mis compañeros de piso montan una empresa con Elena -otra amiga- de bodas, banquetes, bautizos y hacen videos y yo era la encargada de dar al "play-rec".

SB/BH: Es tu primer contacto con los oficios del cine.

CG: Sí. Pero como podéis ver yo entro en el cine por casualidad. No tenía una vocación clara. Para mí el teatro era más cercano.

SB/BH: Poco después decides irte a Nueva York.

CG: En esta época también me doy cuenta de que no estoy tan enamorada de mi novio... él tenía una vena esotérica y veo que nuestros caminos no confluyen... y entonces mi madre me dice "vete a Nueva York con tu hermana". Y yo le digo que quiero estudiar cine. En fin... mi madre insiste: "vete a Nueva York con Blanca"2. Era 1983; yo tenía 21 años.

SB/BH: Y te fuiste a Nueva York...

CG: Sí. El primer año comparto piso con mi hermana Blanca y más gente, pero luego me voy a vivir con unas amigas. En Nueva York empiezo a trabajar desde el primer día. Mi madre siempre nos daba dinero para el billete de avión, pero luego era tu aventura personal.

SB/BH: ¿Cómo fue esta aventura?

CG: Nueva York fue maravilloso en todos los sentidos. Era otra realidad. Yo trabajaba sólo tres días a la semana de camarera y me daba para pagar el alquiler, el teléfono, la escuela... ¡todo!... Vivías al día, no tenías nada extra, pero podías vivir. Para empezar en España no existía ese formato. Ahora sí. Pero en España en ese momento o tenías un trabajo o no lo tenías. Pero en Nueva York vivías de un trabajo a tiempo parcial y además estudiabas.

SB/BH: ¿Dónde estudiabas?

CG: Al principio fui a una escuela -Global Village- que era privada y que no era de cine específicamente, pero luego fui a la universidad. De esta primera escuela en la que estuve lo mejor fue encontrar a Fred Barney, mi maestro. Todavía sigo en contacto con él. Vivía en un loft en el Soho al que invitaba a mucha gente. Entonces empiezo a ir a las reuniones que hace Fred en su casa de gente que trabaja en super- 8 de una manera muy experimental. Me compro enseguida mi primera cámara -las cámaras de super-8 eran muy baratas- y ruedo mi primer corto de súper-8, Porro on the roof (1984) ... En este primer corto está mi hermano Tao ${ }^{3}$, está Blanca... y entro en contacto con un grupo de cineastas. Un amigo italiano me pone en contacto con alumnos de universidad que estudian cine. Me presentan a estudiantes y comienzo a incorporarme a los rodajes. A veces hago claqueta, otras producciones, otras veces sonido -me encantaba el sonido-. Y comienzo a rodar mucho con mi super-8. Utilizaba bobinas de tres minutos, sin sonido y todo lo que hacía lo montaba en cámara. Luego me prestaron una moviola de super-8...

SB/BH: ¿Cómo era trabajar con estudiantes de allí?

CG: Me acuerdo de una anécdota, unos estudiantes iban a rodar un corto y en la primera reunión van y me preguntan “¿qué quieres hacer?”. En ese momento no lo entendí. “¿Maquillaje?” me dijeron... y yo que les digo: "yo quiero aprender a hacer cine”, y me contestan: “ $¡$ ahh... es que como eres una chica! ...”. Tuve por primera vez conciencia de que te podían atribuir un rol profesional diferente sólo por ser mujer. 
SB/BH: Como experiencia vital ¿Nueva York fue todo lo contrario que Londres?

CG: Sí. Nueva York ¡tiene una luz increíble! Te levantas a las seis de la mañana y el cielo está azul. La ciudad es luz, no es como Londres. En Nueva York llevaba un mes y ya conocía a 20 personas. En Londres en nueve meses había conocido sólo a cuatro au pair "pringadas" como yo. Aquí de repente un día estabas en una fiesta de millonarios en Park Avenue bañándote en una piscina cubierta a diez grados bajo cero en el exterior y otro día estabas tratando con un camello en Lower East Side. El arco social era brutal y todo el mundo tenía curiosidad.

SB/BH: En la década de 1980 Nueva York era una ciudad dura.

CG: No tiene nada que ver con el Manhattan de ahora que parece Disneyland, era alucinante... Nueva York era dura y pobre. Yo vivía en la calle 105, entre Broadway y Amsterdam. Debajo de nuestra casa había una especie de tienda de comestibles, toda cubierta de contrachapado con un agujerito donde tú decías "nickelbag", entregabas cinco dólares y te daban una bolsa de marihuana. Eso justo debajo. También estábamos rodeadas de edificios quemados, porque era un momento en el que Nueva York los dueños incendiaban sus propios edificios para cobrar el seguro... muy "heavy metal".

SB/BH: Pero tu sobrevives perfectamente en ese entorno.

CG: En ese momento era más barato vivir en Nueva York que vivir en Madrid. Era muy barato. Era otra época. Había mucha gente soñando con hacer cosas y también muchísimas posibilidades. En Nueva York aprendí que, si tú quieres hacer algo, puedes hacerlo. En Espańa si tu decías "quiero hacer una película”, todo el mundo te contestaría: "no puedes, ¿cómo vas a hacer eso?". Todo eran dificultades. En Nueva York decías "quiero subir a ese edificio por un cable” y te respondían: “¿cómo piensas hacerlo?” Esa era la gran diferencia. Por eso creo que yo hago cine, porque si yo hubiera intentado hacer cine por primera vez en este país [España] no lo hubiera conseguido, pero como yo venía de un lugar [Nueva York] donde todo era posible, yo pensé que todo era posible... y fue una lección de vida.

SB/BH: ¿Por qué dices que fue una lección de vida?

CG: Porque aprendí mucho de mí misma. Me acuerdo de que tenía que buscar un apartamento y me fui a la calle a buscarlo, porque aquellos que veía en los anuncios no tenía dinero para pagarlos... ipues lo encontré! Era como reconocer tu propia fortaleza. Y sobre todo conocí a amigas y amigos que se han quedado para el resto de mi vida.

SB/BH: Muy intenso.

CG: Sí, Nueva York fue mucho... rodé mucho... Allí rodé mi primer cortometraje como profesional, trabajé en el cine, etc. Merry go round (1986) fue mi primer trabajo profesional. Tenía actores, tenía un guion basado en una historia original de un cómic de

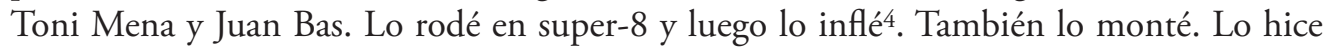
todo sola.

SB/BH: ¿Estabas ya en la universidad?

CG: No. Todavía no había entrado en la universidad. Yo quería haber entrado en enero, pero tuve que esperar a septiembre. También aproveché esos meses para hacer un crosscountry ${ }^{5}$, en un camión. Era un cliente del café donde trabajaba de camarera, venia todos los días y nos hicimos amigos. Un día me dijo que iba a cruzar el país y le dije que 
si podía ir con él. Viajamos durante 25 días, íbamos en el camión a lo largo del país, repartiendo obras de arte a los museos... y yo mientras rodando y rodando con mi super-8.

SB/BH: ¿Ese material lo utilizaste para algo?

CG: No. Ahora que estoy de mudanza tengo que ordenar ese material y ver qué puedo hacer con ello... pero se verá mucha carretera porque resulta que el señor estaba casado y yo no podía grabarle... bueno, cosas de la vida...

SB/BH: Consigues entrar en la universidad.

CG: Sí, en el City College of New York (CUNY). Tuve que hacer allí el examen de acceso, pero me resultó fácil entrar. A ver, yo no quería tener un título y para poder terminar tenía que hacer asignaturas de todo tipo, pero yo sólo quería hacer cine. Así que elegí las asignaturas que quería y cuando vi que ya no me dejaban seguir, dejé la universidad. Estuve año y medio allí. Fue maravilloso. Incluso Spike Lee vino a clase a enseñarnos su primera película, Shés Gotta Have It (1986). También tuve una maestra afroamericana de guion maravillosa, otro profesor de dirección que estaba muy bien... rodábamos mucho, yo hice de actriz muchas veces.

SB/BH: ¿En la universidad ya rodabais en $16 \mathrm{~mm}$ ?

CG: Sí, rodábamos todo en $16 \mathrm{~mm}$. Tu ibas a hablar con el encargado del material de la universidad y le decías que querías rodar y podías acceder a las cámaras, al nagra, luces... y en la moviola entrabas y podías montar toda la noche. Había muchos sitios alternativos. Había un sitio que se llamaba Millenium que alquilabas una moviola y era el paraíso. Allí edité Merry go round.

SB/BH: ¿Te volvieron a preguntar si querías ser maquilladora?

CG: No, nunca más. De hecho, creo que al final soy una de las pocas personas de mi clase que sí ha tenido una carrera dentro del mundo del cine, aunque también había un chico, Joseph Vasquez, que hizo una gran película titulada Hanging with the Homeboys (1991), pero se murió muy pronto.

SB/BH: Tú, tu hermana Blanca y unas amigas formáis un grupo musical: Xoxonees ¿Cómo surge la idea?

CG: Mi hermana Blanca no sabe vivir si no está encima de un escenario. Blanca es el motor real. Estábamos viviendo en la calle 105 con unas amigas y de repente surgió la idea de montar un grupo musical. Así de la nada... e hicimos dos canciones, así de la nada... [risas]. Porque, además, si tu venías a visitarnos y teníamos un show en ese momento, tú te metías en el show. Casi obligado. Si venías a visitarnos entrabas en el espectáculo. Si uno sabía hacer trapecio, pues le metíamos como trapecista... Cualquier cosa que supieras hacer nos servía.

Actuamos en un montón de sitios. ¡Nuestra primera actuación fue tan bonita!... actuamos en un bar que se llamaba The Blue Rose y que hacía esquina con nuestra calle. Lo llevaba una griega con un moño hasta aquí [señala $30 \mathrm{cms}$ por encima de su cabeza] que era la dueña. Era un bar cutre, no... lo siguiente... Porque Nueva York era eso -echo de menos las cosas cutres, odio que ahora todo sea bonito-. Además, la dueña tenía a su madre enferma en una cama detrás de la barra. Así era la griega, y allí hicimos nuestra primera actuación como Xoxonees. Fue total. Muy divertido.

SB/BH: Las letras de las canciones eran antirracistas, anti-depilación, anticontestador automático... ¿Quién componía las letras? 
CG: Pues Blanca, Montse, mi hermano Tao -que llegó a Nueva York un par de años más tarde-. Yo no escribía. Recuerdo que hablábamos del ajo biológico [risas]... ¡Éramos un poco adelantadas a nuestro tiempo!

\section{Notas}

${ }^{1}$ La presente entrevista ha sido realizada con el apoyo del Proyecto I+D+i "Cine y televisión 1986-

1995: modernidad y emergencia de la cultura global” (CSO2016-78354-P). Ministerio de Economía y Competitividad, Gobierno de España.

${ }^{2}$ Blanca Li (Blanca María Gutiérrez Ortiz) hermana de la entrevistada, es coreógrafa, bailarina y artista.

${ }^{3}$ Tao Gutiérrez, hermano de la entrevistada, es músico, compositor y artista.

4 "Inflar" super-8 significa convertirlo a $16 \mathrm{~mm}$.

${ }^{5}$ Consiste en cruzar EE. UU. de forma económica, normalmente en tren u otros transportes baratos. 